\title{
Somatic Embryogenesis in Pearl Millet (Pennisetum Glaucum (L) R.Br.) Using Light and Electron Microscopy
}

\author{
Santha. $\mathrm{B}^{1^{*}}$, Seetharama $\mathrm{N}^{2}$ \\ ${ }^{I}$ Department of Plant Physiology, ANGRAU, Hyderabad \& ICRISAT, Patancheru \\ ${ }^{2}$ Fmr. Director (Sorghum/ICAR), Fmr. R\&D Scientist ICRISAT, Patancheru
}

\begin{abstract}
The morphology and histology of somatic embryogenesis were examined using embryogenic calli derived from immature inflorescences of pearl millet using light and electron microscopic techniques. Young immature inflorescences, $30-35$ days old (2.5 cm long) were cultured on LS medium supplemented with $2.0 \mathrm{mgL} \mathrm{L}^{-}$ ${ }^{1}$ of 2, 4-D and $0.5 \mathrm{mgL}^{-1}$ of kinetin. The primary callus initiated was non-embryogenic, loose, white but differentiated rapidly into pale yellow, nodular and friable embryogenic callus within 2 weeks. Histological studies revealed the formation of somatic embryos and their maturation. Initial stages of somatic embryo induction showed calli with internal segmenting divisions, which gave rise to discrete groups of cells. Continued divisions and organization in some discrete groups formed globular structures, presumably proembryoids, which showed a distinct epidermis. Further these structures developed to form somatic embryos with a wellorganized bipolar structure showing embryonic axis, scutellum, coleoptile and coleorhiza. Multiple shoots (5-6) were produced from each embryo when transferred to MS regeneration medium supplemented with hormonal combinations, viz., $B A P+I B A, 2.0+0.5 \mathrm{mg} L^{-1}$ which further developed into complete plantlets.
\end{abstract}

Key words: Immature inflorescences, callusing, embryogenic cells, morphology, histology

Abbreviations: MS - Murashige \& Skoog, 2,4-D - 2, 4, dichlorophenoxyacetic acid, LS - Linsmaeir \& Skoog, Kn-kinetin, BAP-6-benzylaminopurine, IBA-Indole 3- butyric acid

\section{Introduction}

Pearl millet is an important food, feed and fodder crop of the semi-arid tropics. In spite of its good adaptability to adverse growth conditions, there is a need for improvement in for its nutritional quality, resistance to fungal diseases and other insects and for further increase in stress resistance. Plant transformation techniques have proven to be very useful for crop improvement and commercial crop production. An efficient and reproducible regeneration system is a pre-requisite for applying in vitro techniques in genetic transformation studies. In vitro culture of multicellular explants has been carried out in all major cereal crops during the past 20 years, and plant regeneration has been obtained by either organogenesis or somatic embryogenesis [1,2]. In pearl millet, procedures for plant regeneration by somatic embryogenesis have been described for a range of tissues such as immature embryos [3], immature inflorescences [4] and shoot apices [5, 6]. Extensive evidence was available for the regeneration via somatic embryogenesis in pearl millet and all of the major species of cereals and grasses [7] and it has been suggested that this may indeed be a common method of plant regeneration in tissue cultures of the Gramineae [8].

The somatic embryos arise from single cells, either directly or following the formation of a mass of proembryogenic cells. This has been previously demonstrated in the Gramineae $[8,9$, and 10]. The nature of embryogenic calli of pearl millet were described to be compact, organized and white to pale yellow in colour [3]. However, limitations with respect to their application are seen in the inability to reproduce similar successes in efficient regeneration across the genotypes by applying the same protocol and little is known about the behavior of different explants within a given genotype. A thorough understanding of the regulation of the in vitro system is therefore necessary to undertake transformation studies. Also very little information is available on the histology of somatic embryo induction and development. The present study describes the developmental stages of embryo formation and maturation using immature inflorescence as the source of explant for callus initiation and somatic embryogenesis, making use of light and scanning electron microscopy.

\section{Materials and methods}

\section{Callusing and regeneration from Immature inflorescence explant}

Immature inflorescences $(2.5 \mathrm{~cm}$ long) of pearl millet genotype 843-B were collected from 30-40 days old glasshouse-grown plants before the emergence of the boot leaf of the main shoot. The leaves were removed sequentially and surface-sterilized by swabbing with $70 \%$ ethanol prior to culture. The inflorescences were taken on a sterile petriplate and cut into 4-5 pieces using a sterilized forceps and a scalpel. They were cultured 
on the medium with the base touching the medium gelled with $0.8 \%(\mathrm{w} / \mathrm{v})$ agar at $\mathrm{pH} 5.8$. The LS [11] medium fortified with myo-inositol (Sigma, St. Louis, MO, USA), thiamine hydrochloride (Sigma, St. Louis, MO, USA), mineral nutrients and $3 \%$ sucrose was used for callusing. The hormonal combination $\left(2.0 \mathrm{mgL}^{-1}\right.$ of 2 , 4$\mathrm{D}$ and $0.5 \mathrm{mgL}^{-1}$ of $\mathrm{kn}$ ) that gave the best response from the initial studies was taken for callus induction. Initially the explants for callusing were incubated under dark conditions at $25 \pm 2^{0} \mathrm{C}$ till callus initiation and proliferation. The embryogenic calli were subcultured on fresh medium with same hormonal combination at an interval of 15 days for proliferation of somatic embryos and maintenance of cultures for a prolonged period at $25 \pm 2^{0} \mathrm{C}$ with $16 \mathrm{~h}$ photoperiod of $45-55 \mu \mathrm{mol} \mathrm{m}^{-2} \mathrm{~s}^{-1}$ light, using fluorescent tubes (Philips, 36W). The embryogenic callus derived from immature inflorescences after subsequent subcultures were transferred to MS [12] regeneration medium supplemented with hormonal combinations, viz., BAP + IBA, $2.0+0.5 \mathrm{mg} \mathrm{L}^{-1}$. The regenerated shoots were then transferred to MS basal medium for rooting. The rooted plants were hardened in jiffy cups containing soil rite mix for a week and the plantlets were finally shifted to glasshouse and were grown to maturity.

\section{Histological studies of somatic embryogenesis}

2.1 Light microscopy

Embryogenic and non-embryogenic calli (35-40 days old) obtained from immature inflorescence explants at different stages were fixed in acetic acid: $95 \%$ ethanol, dehydrated through a series of ethanol solutions, followed by paraffin embedding. The material embedded in the wax was trimmed to remove all the extra wax in and around the tissue and was sectioned (4 $\mu \mathrm{m}$ thickness), dried, deparaffinised and then stained serially stained serially with $1 \%(\mathrm{w} / \mathrm{v})$ safranin $(12 \mathrm{~h})$ followed by $2 \%(\mathrm{w} / \mathrm{v})$ fast green $(25-30 \mathrm{~min})$ and $1 \%$ $(\mathrm{w} / \mathrm{v})$ haematoxylin $(1 \mathrm{~min})$ and $1 \%(\mathrm{w} / \mathrm{v})$ eosin $(1 \mathrm{~min})$ for double-staining, followed by washing. The slides were finally mounted using a drop of DPX mounting agent [10]. All the slides were observed using a compound light microscope with 10 or $20 \mathrm{X}$ magnifications and photographed with a 100 ASA film.

\subsection{Scanning electron microscopy}

Calli at different developmental stages (non-embryogenic and embryogenic) were selected and fixed in $3 \%$ glutaraldehyde (EM grade prepared in $0.1 \mathrm{M}$ sodium phosphate buffer with a $\mathrm{pH}$ set to 7.2 ) for 3-4 h, dehydrated with a series of acetone solution. For preparing the samples for scanning, the samples were treated with a series of acetone: amyl acetate (2:1) for $2 \mathrm{~min}$, followed by acetone: amyl acetate (1:1), and acetone: amyl acetate (1:2). The samples were dehydrated completely by critical point drying (CPD) and were fixed onto metal stubs for coating with tungsten. The tungsten coated samples were scanned thereafter with a Hitachi $-\mathrm{S}$ 520 scanning electron microscope with varying magnifications under $10 \mathrm{KV}$ voltage using standard procedure [13].

\section{Results}

\section{Morphology of callus induction, somatic embryogenesis and regeneration}

Optimized in vitro conditions were used for callus induction, somatic embryogenesis and regeneration. Callus initiated from immature inflorescences explants (Fig 1A) by 12-14 days after inoculation from the inflorescence axis and spikelets (Fig 1B). The primary callus was non-embryogenic, loose, white and yellowish but differentiated rapidly into a pale yellow, nodular, and friable embryogenic callus (Fig 1C) within 2 weeks. Most of the callus turned embryogenic and only a very minor portion remained watery, yellow and soft, nonembryogenic, which was separated out during subculture. Embryogenic callus was separated from the primary culture and sub-cultured onto fresh medium at regular intervals for prolonged periods for further proliferation and development, which formed globular structures (Fig 1D). These globular structures developed into somatic embryos (Fig 1E) on the surface of the callus when maintained on the same LS medium for 2-3 weeks.

The frequency of embryogenesis increased with consecutive subcultures. The embryogenic calli on transfer to regeneration medium produced whitish embryoids, which later differentiated to plantlets on same medium (Fig 1F). The plantlets rooted 1-2 weeks later on MS basal medium (Fig 1H), and were then transferred to jiffy cups for hardening for a week. The plants were then transferred to glasshouse and were grown to maturity (Fig 1I)

\section{Histology of callus induction, somatic embryogenesis and regeneration}

\subsection{Induction of callus}

The section of immature inflorescence segment showed the central inflorescence axis enclosed with peripheral floral primordia (Fig 2A). The floral primordia appeared as protuberances of meristematic cells, richly dividing cytoplasmic cells at the tip of each floral primordium. The section passing through the inflorescence segment 8 days after culture showed a single layered epidermis with parenchymatous cells (Fig 2B). A section passing through 10-15 day culture revealed proliferation of cells and their meristematic activity 
(Fig 2C). This resulted in the formation of a peripheral meristematic zone with small, richly cytoplasmic cells, with prominent nuclei without any intercellular spaces (Fig 2D). The surface scan of the callus also showed the differentiating non-embryogenic callus (Fig 4A).

\subsection{Development of embryogenic tissue}

After 20-22 days of culturing, these peripheral richly dividing cells differentiated into medium-sized, highly cytoplasmic cells (Fig 2E-F). After 30-35 days after culture, these medium-sized cells occupied several layers immediately after the epidermis (Fig 2G-H), producing a lobed callus (Fig 2I, 4B). A rapid localized proliferation was observed in the zone of meristematic activity, producing a lobed callus showing the absence of vascular connection with the parent tissue (Fig 3A). These embryogenic cells were easily distinguished from the protective epidermal layer due to their greater size and dense cytoplasm (Fig 3B) representing different stages of differentiation. Internal segmenting divisions in many of these cells gave rise to discrete groups of cells on the callus surface and each group was distinct and separated from each other cells by a thick wall (Fig 3C). The development of vascular initials (Fig 3D) within the lobed callus further revealed features of early embryogenic callus development. This lobed structure is termed embryogenic tissue, which contained several layers of embryogenic cells. Continued divisions and organization in some of these discrete groups formed rounded structures-proembryoids which showed a distinct epidermis (Fig 3E, 4C). Each proembryoid showed vacuolated cells at the basal portion, and an upper ovate portion containing small densely cytoplasmic cells without intercellular spaces (Fig 3F).

\subsection{Maturation of Somatic embryos}

Further differentiation of these structures led to the formation of globular somatic embryos and embryoids, which appeared on the surface of the callus after breaking through the epidermis as confirmed through scanning electron microscopy (Fig 4D-E). These globular structures developed into somatic embryos on the surface of the callus when maintained by subculturing medium for 3-4 weeks. The development of the embryoids was not synchronous, and therefore embryoids at various stages of development could be found adjacent to each other. The large, peripheral cells proliferated in many embryoids to give rise to secondary embryogenic callus tissue and secondary embryoids (Fig 3G).

\subsection{Germination of somatic embryos}

The globular somatic embryos formed were separated and cultured on MS regeneration medium for maturation and germination of the somatic embryos. The globular somatic embryos formed were round. Polarity was established in the embryoids followed by cotyledon differentiation. Cotyledon initiation occurred at one end of the oval shaped somatic embryos at the late globular stage (Fig 3H). Further development of these bipolar structures led to the formation of typical embryoids, with a well-organized embryonic axis, scutellum, coleoptile and coleorhiza (Fig 3I). Globular suspensors were found attached to the somatic embryos (Fig 4F) as observed with scanning electron microscopy. Multiple shoots (5-6) were produced from each embryoid, which further differentiated into whole plantlets. 


\section{Figures}
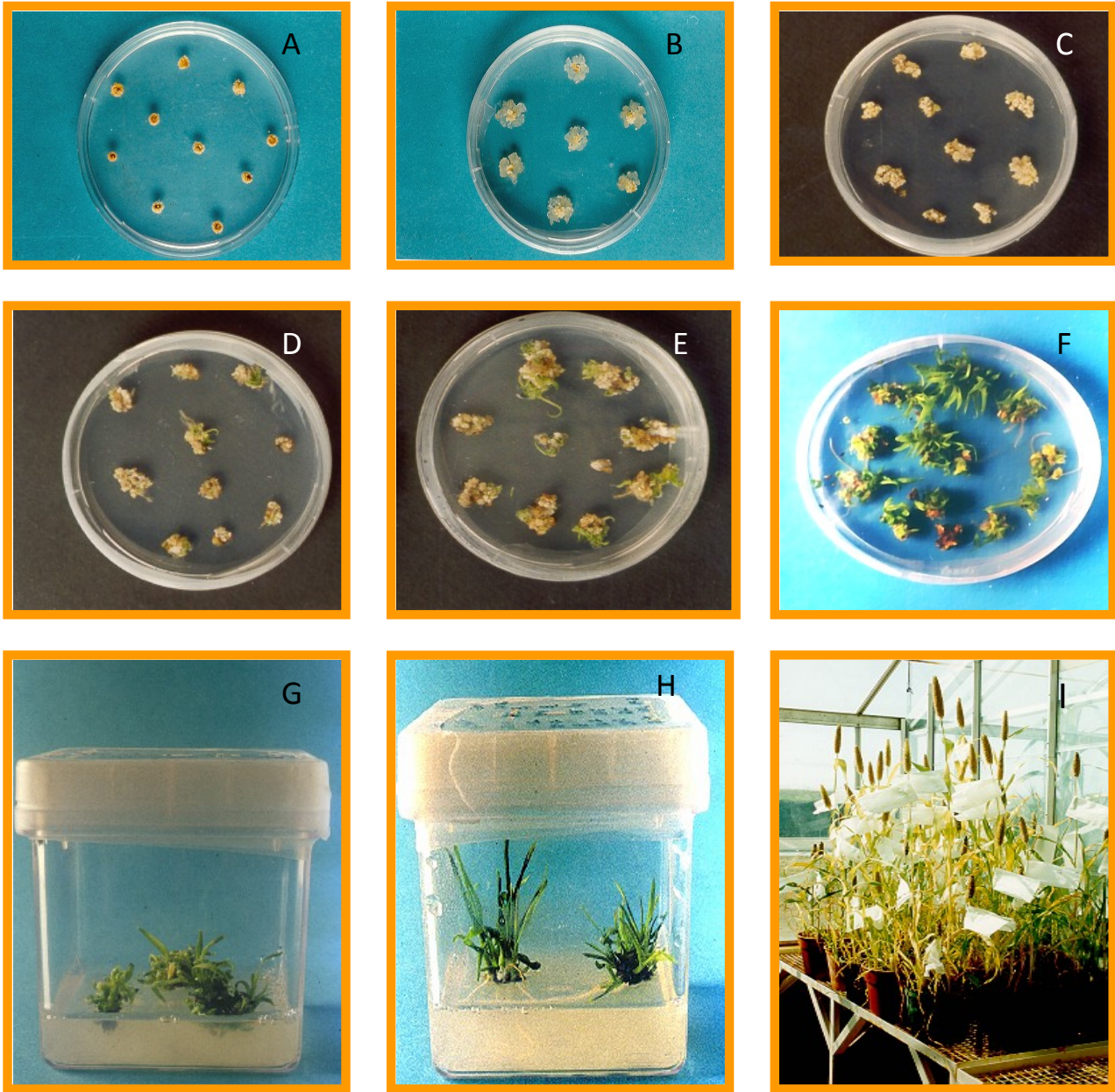

Figure 1: Immature inflorescence regeneration system
A. Sections of immature inflorescence explant
B. Callus initiation from explant on LS medium
C. Completely differentiated embryogenic calli
D. Somatic embryo formation
E. Regeneration initiation from embryogenic calli
F. Regenerating calli on MS regeneration medium
G. Regenerating shoots in magenta boxes
H. Rooting regenerants on MS basal medium 

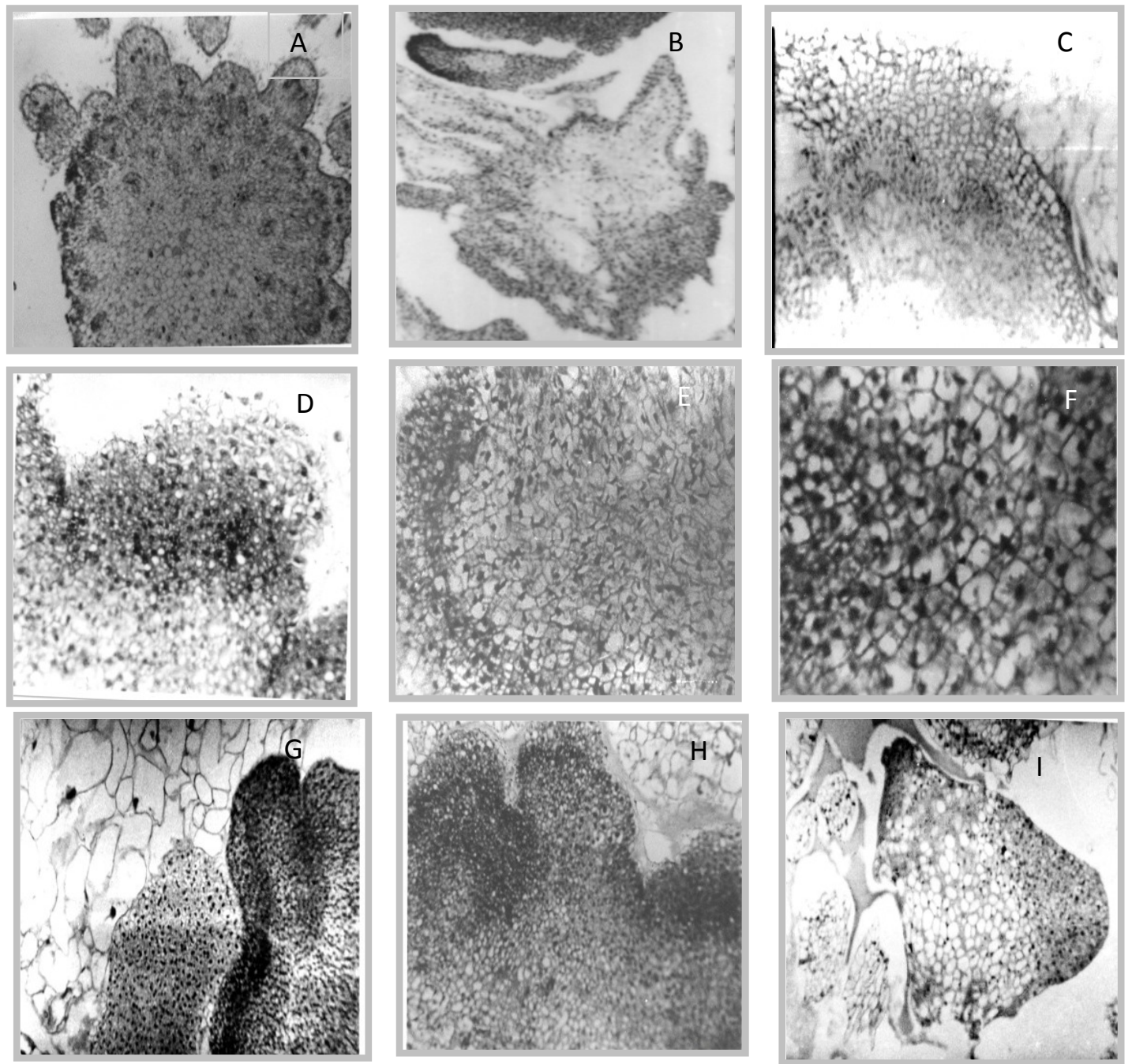

Figure 2: Light microscopic studies on callus induction from immature inflorescence explants

A) Section of immature inflorescence explant showing central inflorescence axis with peripheral floral primordia (20X).

B) Section passing through explants showing actively dividing cells at the tip of each leaf primordium 8 days after subculture (10X).

C) Section showing cell proliferation below the epidermis 10-15 days after subculture (20X).

D) Peripheral meristematic zone with small, cytoplasmic cells and dense nuclei (20X).

E) Richly dividing parenchymatous cells showing medium-sized richly cytoplasmic cells (20X).

F) Closer view of medium-sized and richly dividing cells of $\mathrm{E}$ with no intercellular spaces (20X).

G) The richly dividing cells occupying several layers below the epidermis 30-35 days after subculture (20X).

H) Several layers of embryogenic cells below the epidermis producing lobed structures (20X).

I) Lobed callus produced by the richly dividing cells on the callus surface for the development of embryogenic tissue (10X). 

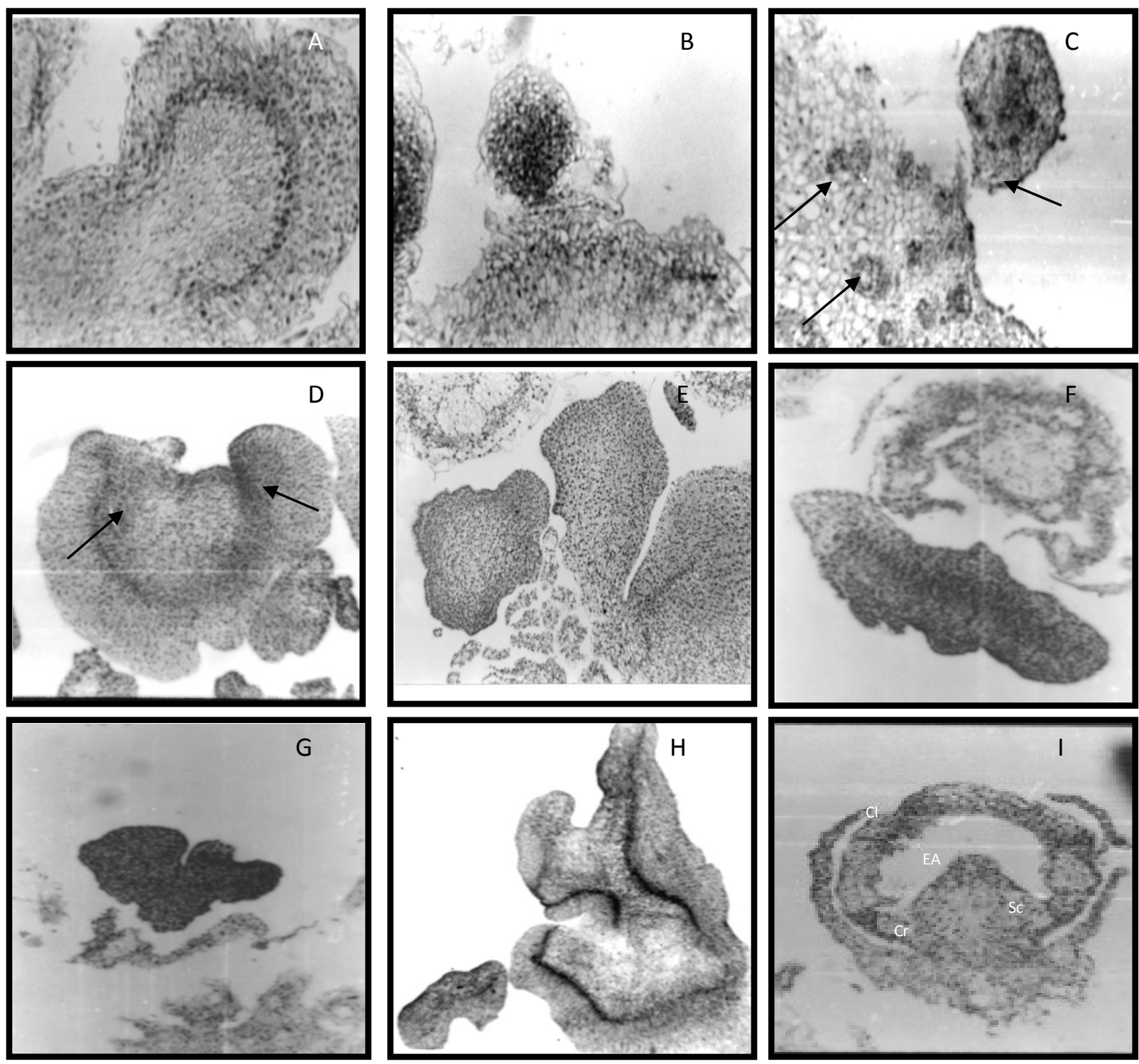

Figure 3: Light microscopic studies on somatic embryogenesis and their maturation

A) Formative stage of a lobed structure through vigorous divisions in the meristematic zone, revealing early embryogenic callus development.

B) Completely formed lobed callus 30-35 days after culture named as embryogenic tissue showing richly dividing cells with prominent nucleus.

C) Internal segementing divisions of these cells gave rise to discrete groups of cells (left arrows), some of which were separated by breaking through the epidermis to form oval shaped embryoid-like structures with thick cell wall (right arrow).

D) Heart shaped proembryoid with basal vacuolated cells and an upper ovate portion with dense cytoplasmic cells showing the development of vascular initials (arrows).

E) Continued divisions and organization of the discrete groups lead to the formation of proembryoids with a distinct epidermis

F) Proembryoid showing vacuolated cells at the basal portion and an upper ovate portion containing small densely cytoplasmic cells without any intercellular spaces.

G) Secondary embryo formation resulted from the proliferation of peripheral cells of embryogenic tissue.

H) Section of a mature somatic embryo with scutellum formation and vascular initials

I) Typical mature embryo showing the bipolar structure, with well-organized embryonic axis (EA), scutellum ( $\mathrm{Sc})$. coleoptile $(\mathrm{Cl})$ and coleorhiza $(\mathrm{Cr})$. 

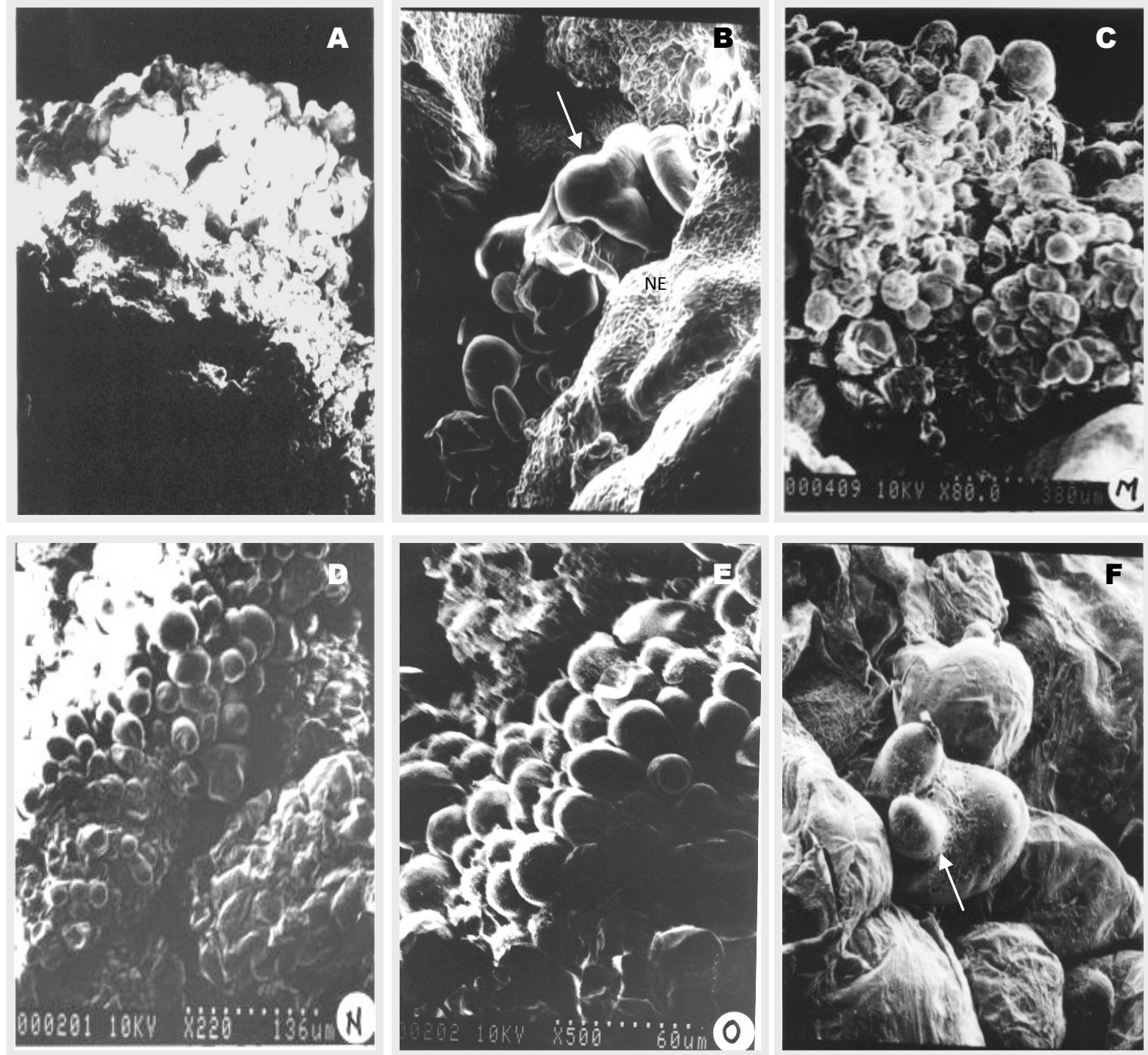

Figure 4: Scanning electron photomicrographs showing somatic embryogenesis in pearl millet

A) Differentiating non-embryogenic callus $(10 \mathrm{KV} \times 70,430 \mu \mathrm{m})$.

B) The differentiation of non-embryogenic callus (NE) into lobed embryogenic callus (arrow) (10 $\mathrm{KV} \times 20,1500 \mu \mathrm{m})$.

C) Globular structures on the callus surface 45 days after culture initiation $(10 \mathrm{KV} \times 80,524 \mu \mathrm{m})$.

D) Further differentiated globular somatic embryos as scanned at $10 \mathrm{KV} \times 220,136 \mu \mathrm{m}$.

E) Closer scan of somatic embryos at $10 \mathrm{KV} \times 500,60 \mu \mathrm{m}$.

F) Globular suspensors (as indicated by arrow) attached to somatic embryos $(10 \mathrm{KV} \times 300,100 \mu \mathrm{m})$. 


\section{Discussion}

Embryogenic explant is crucial for any regeneration system [14]. The selection of the explant, its age and in vitro conditions form important factors that affect any regeneration system. It is an established fact that the growth hormones influence the establishment of embryogenic callus cultures [1]. The results in the previous study also revealed that exogenous hormone levels regulated somatic embryogenesis and subsequent regeneration in pearl millet. Cells proliferated from explants in the presence of 2, 4-D in all the combinations. The proportion of callus induction was found to be more with higher levels of 2, 4-D (2.5 mgL $\mathrm{mL}^{-1}$ of 2, 4-D) and therefore calli obtained from this combination were taken for light and scanning electron microscopy in the present study. The callus induction and subsequent plant regeneration from immature inflorescence-derived calli through somatic embryogenic pathway was elucidated by studying the histology of somatic embryogenic pathway. The primary callus initiated was non-embryogenic, loose, and white but differentiated rapidly into pale yellow, nodular and friable embryogenic callus within 2 weeks. Botti and Vasil [5] also reported that the initial primary callus was soft and non-embryogenic in pearl millet cultures, which later differentiated into white to pale yellow, compact embryogenic callus in localized areas. These results are also in accordance to those reported by Vasil and Vasil [3]. The hormone 2, 4-D is an auxin analogue, which has the ability to induce cell proliferation at low concentrations in a wide variety of graminaceous cultures. In the presence of 2, 4-D, the cells express their embryogenic competence, richly divide and produce meristematic zones that further undergo active divisions [1]. The importance of auxin to cytokinin ratio in the control of regeneration is well known as reported by Skoog and Miller [15]. The 2, 4-D to kinetin ratios significantly influenced the responses for callus induction and differentiation in this study as well. Lower 2, 4-D to kinetin combinations responded better giving high proportion of embryogenic calli, which were significantly different from that of higher 2, 4-D to kinetin combinations making it clear that higher auxin levels (irrespective of kinetin) are needed for callus induction, while lower auxin to kinetin combination are responsive for callus differentiation and further somatic embryogenesis. The results were in accordance to those reported by Vasil and Vasil [8]. Light and scanning electron microscopic studies further revealed the characteristics of embryogenic callus cultures. At a later stage few of the embryogenic cells that were small and richly cytoplasmic dedifferentiate into large elongated and vacuolar cells that lose starch grains and become non-embryogenic. The cultures were found to be a mixture of embryogenic and non-embryogenic callus, and therefore the embryogenic sectors were visually selected and cultured on fresh medium at regular intervals. These results are in accordance to those reported by several workers $[5,9$, and 10]. Therefore, the embryogenic callus was visually selected and sub-cultured separately on the medium. The formation of compact tissue comprising of small and richly cytoplasmic cell, as observed in the present investigation, is a common feature in most of the cereal in vitro cultures [8]. These cells then differentiated by attaining embryogenic competence during early stages of culture as reported by earlier investigators [10]. The gradual differentiation of callus from peripheral meristematic cells led to the formation of layers of embryogenic cells, which further differentiated into globular embryos. The scutellum, coleoptile and coleorhiza are the unique characteristics of a grass embryo [3]. The discrete embryo-like structures formed in pearl millet also showed a scutellum, coleoptile and coleorhiza with an independent vascular system that is not connected to the maternal tissue (Fig 3I) in cultured immature inflorescences of present investigation suggesting that they are identical to the sexually produced normal grass embryos. These results were consistent with the descriptions produced by earlier investigators [3]. The sequence of cell separation, internal segmenting divisions finally leading to the development of embryoids with bipolar structure similar to zygotic embryo provide further evidence for the single cell origin of embryoids as reported by other researchers $[8,16]$. Successful regeneration from embryogenic cultures has also been reported by several workers in Graminae [8, 17]. A significant aspect of plant regeneration via somatic embryogenesis is that it overcomes many of the disadvantages of regeneration from adventitious shoot meristem of multicellular origin. The somatic embryos arise from single cells, either directly or following the formation of a mass of proembryonic cells $[8,9$, and 10$]$.

\section{Conclusions}

A significant aspect of plant regeneration via somatic embryogenesis is that it overcomes many of the disadvantages of regeneration from adventitious shoot meristems of multicellular origin. Thus, it is concluded that such a regeneration system would be the most appropriate for deploying in genetic transformation experiments in pearl millet. 


\section{Acknowledgement}

The first author thanks Genetic Transformation Lab, ICRISAT for providing research facilities and ANGRAU for providing financial assistance. We thank Mr. Ahead and Mrs. Sharada (National Institute of Nutrition, Tarnaka, Hyderabad) for extending the microtome facilities.

\section{References}

[1] Vasil I.K, Developing cell and tissue culture systems for the improvement of cereal and grass crops, Journal of Plant Physiology 128, 1987, 193-218.

[2] S Bhaskaran, and R.H. Smith, Cell biology and molecular genetics: a review on regeneration in cereal tissue culture, Crop Science, 30,1990, 1328-1336.

[3] Vasil V, and I.K Vasil, Somatic embryogenesis and plant regeneration from tissue cultures of Pennisetum americanum and Pennisetum americanum $\times$ Pennisetum purpureum hybrid, Americal Journal of Botany, 68, 1981, 864-872.

[4] Pius J, L. George, S. Eapen, and P.S Rao, Enhanced plant regeneration in pearl millet (Pennisetum americanum) by ethylene inhibitors and cefatoxime, Plant Cell Tissue Organ Culture, 32, 1993, 91.

[5] Botti C, and I.K.Vasil, Plant regeneration by somatic embryogenesis from parts of cultured mature embryos of Pennisetum americium (L.) K. Schum. Z, Pflanzenphysiology 111, 1983, 319-325.

[6] Mythili P.K, A. Madhavi, V.D. Reddy, N. Seetharama, Efficient regeneration of pearl millet (Pennisetum glaucum (L.) R. Br.) from shoot tip cultures, Indian Journal of Experimental Biology, 39, 2001, 1274-1279.

[7] Morrish F, V. Vasil, and I.K. Vasil, Developmental morphogenesis and genetic manipulation in tissue and cell cultures of the Gramineae, Advances in Genetics, 24, 1987, 431-499.

[8] Vasil V, and I.K Vasil, The ontogeny of somatic embryos of Pennisetum americanum (L.) K. Schum: in cultured immature embryos, Botanical Gazette, 143, 1982, 454-465.

[9] Botti C, and I.K.Vasil, The ontogeny of somatic embryos of Pennisetum americanum (L.) K. Schum. II. In cultured immature inflorescences, Canadian Journal of Botany, 62, 1984, 1629-1634.

[10] Lu C, and I.K. Vasil, Histology of somatic embryogenesis in Panicum maximum jacq. (Guinea Grass), American Journal of Botany 72, 1985, 1908-1913.

[11] Linsmaier E.M, and F. Skoog Organic growth factor requirements of tobacco tissue cultures, Physiologia Plantarum, 18, 1965, 100 127.

[12] Murashige T, and F. Skoog, A revised medium for rapid growth and bioassay with tobacco tissue cultures, Physiologia Plantarum 15, 1962, 493-497.

[13] Santos A.V.P.D, and R.D Machado, A scanning electron microscope study of Theobroma cacao somatic embryogenesis, Annals of Botany, 64, 1989, 293-296.

[14] Talwar M, and A. Rashid, Factors affecting formation of somatic embryos and embryogenic callus from unemerged inflorescences of a graminaceous crop Pennisetum, Annals of Botany 66, 1980, 17-21.

[15] Skoog F, and C.O Miller, Chemical regulation of growth and organ formation in plant tissues cultured in vitro, Symposium of Society for experimental biology $11,1957,18-231$.

[16] Halperin W, Morphogenesis in cell cultures, Annual Reviews of Plant Physiology, 21, 1969, 395-418.

[17] Vasil I.K., Somatic embryogenesis and plant regeneration in cereals and grasses, in A Fujiwara (Ed.) Plant Tissue Culture, (Maruzen, Tokyo, 1982) 101-104. 